\title{
Molecular targets of curcumin in breast cancer (Review)
}

\author{
XINQIANG SONG ${ }^{1,2}$, MU ZHANG $^{3}$, ERQIN DAI $^{3}$ and YUAN LUO ${ }^{4}$ \\ ${ }^{1}$ Department of Life Sciences; ${ }^{2}$ Institute for Conservation and Utilization of Agro-Bioresources in Dabie Mountains, \\ Xinyang Normal University; ${ }^{3}$ Hospital Attached to Xinyang Normal University, Xinyang, Henan 464000; \\ ${ }^{4}$ State Key Laboratory of Toxicology and Medical Countermeasures, Institutes of Pharmacology and Toxicology, \\ Academy of Military Medical Sciences, Beijing 100850, P.R. China
}

Received March 7, 2018; Accepted October 25, 2018

DOI: $10.3892 / \mathrm{mmr} .2018 .9665$

\begin{abstract}
Curcumin (diferuloylmethane), an orange-yellow component of turmeric or curry powder, is a polyphenol natural product isolated from the rhizome of Curcuma longa. For centuries, curcumin has been used in medicinal preparations and as a food colorant. In recent years, extensive in vitro and in vivo studies have suggested that curcumin possesses activity against cancer, viral infection, arthritis, amyloid aggregation, oxidation and inflammation. Curcumin exerts anticancer effects primarily by activating apoptotic pathways in cancer cells and inhibiting pro-cancer processes, including inflammation, angiogenesis and metastasis. Curcumin targets numerous signaling pathways associated with cancer therapy, including pathways mediated by $\mathrm{p} 53$, Ras, phosphatidylinositol-3-kinase, protein kinase $B$, Wnt- $\beta$ catenin and mammalian target of rapamycin. Clinical studies have demonstrated that curcumin alone or combined with other drugs exhibits promising anticancer activity in patients with breast cancer without adverse effects. In the present review, the chemistry and bioavailability of curcumin and its molecular targets in breast cancer are discussed. Future research
\end{abstract}

Correspondence to: Dr Xinqiang Song, Department of Life Sciences, Xinyang Normal University, 237 Nanhu Road, Xinyang, Henan 464000, P.R. China

E-mail: xqsong2012@126.com

Dr Yuan Luo, State Key Laboratory of Toxicology and Medical Countermeasures, Institutes of Pharmacology and Toxicology, Academy of Military Medical Sciences, 27 Bei Taiping Road, Beijing 100850, P.R. China

E-mail: luoyuan2006@163.com

Abbreviations: Bcl-xL, B-cell lymphoma-extra large; CDK, cyclin-dependent kinase; CXCL, chemokine (C-X-C motif) ligand; GSK3 $\beta$, glycogen synthase kinase-3 $\beta$; mTOR, mammalian target

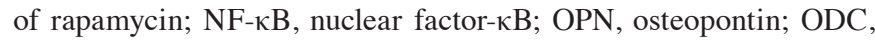
ornithine decarboxylase; PI3K, phosphatidylinositol-3-kinase; TNBC, triple-negative breast cancer; uPA, urinary plasminogen activator; VEGF, vascular endothelial growth factor

Key words: breast cancer, curcumin, molecular targets, metabolism, bioavailability, transcription factors, signaling pathway directions are discussed to further understand this promising natural product.

\section{Contents}

1. Introduction

2. Metabolism

3. Bioavailability

4. Molecular targets of curcumin for breast cancer therapy

5. Potential risks and adverse side effects of curcumin

6. Conclusion

\section{Introduction}

Breast cancer is the most common cancer in women worldwide; it accounts for $\sim 25 \%$ of all female malignancies and its prevalence is higher in developed countries (1). Breast cancer is the second leading cause of cancer-associated mortality among women in the world $(1,2)$. Current therapeutic strategies for breast cancer, which include surgery, chemotherapy and radiotherapy, may lack efficacy due to a high risk of relapse, poor patient response and the emergence of drug resistance (3). This supports the requirement to understand the genetic and biochemical factors underlying the uncontrolled cell proliferation in breast cancer, in order to develop novel therapies.

In breast cancer tissues, the overexpression of cyclin-dependent kinases (CDKs) and underexpression of tumor suppressor protein p53 is frequently observed (4). Simultaneously, a number of cell cycle regulatory proteins are downregulated, including the CDK inhibitors, p21, p27 and p57 (5-8). Targeting these molecules may be effective in breast cancer therapy (5), and natural products that target these molecules are particularly attractive as they are likely to have high therapeutic potential and less likely to induce adverse effects $(9,10)$. Plants are an excellent source of bioactive natural compounds (7,11-13), and polyphenolic compounds from plants frequently exert multiple therapeutic effects (14-16). The polyphenolic phytochemical curcumin [1,7-bis(4-hydroxy-3-methoxyphenyl)-1, 6-heptadiene-3,5-dione; Fig. 1], isolated from the powdered rhizome of Curcuma longa L. (Zingiberaceae) $(17,18)$, interacts with numerous biological targets, including inflammatory mediators, growth factors, enzymes, carrier proteins, metal 
ions, tumor suppressors, transcription factors, oncoproteins and cellular nucleic acids (19-21). Discovered in 1815 by Vogel and Pelletier as a yellow pigment (4), curcumin has been consumed for $>2,000$ years in Asian countries, due to its various medicinal properties against human diseases, including cancer and auto-immune diseases (10,17,22-29).

In the present report, the molecular targets of curcumin and its potential benefits as a drug for breast cancer therapy are critically reviewed.

\section{Metabolism}

One of the limitations in the use of curcumin as a therapeutic agent is its rapid metabolism. Following absorption, the double bonds in the heptadienedione chain are reduced, leading to the production of a series of active metabolites (30).

Alcohol dehydrogenase reduces curcumin to tetra- and hexahydrocurcumin in the liver, and an unidentified microsomal enzyme leads to the formation of di- and octa-hydrocurcumin (31). Hexahydrocurcuminol, hexahydrocurcumin, tetrahydrocurcumin, dihydrocurcumin and their glucuronide and sulfate conjugates have been detected in hepatocytes (31). Curcumin and its reduced metabolites undergo glucuronidation and are converted into curcumin glucuronide and curcumin sulfate (32).

\section{Bioavailability}

Curcumin has very low water solubility and a high oil-water partition coefficient. Its water solubility is low at acidic and neutral $\mathrm{pH}$; whereas, curcumin is soluble at an alkaline $\mathrm{pH}$ (33). However, the compound decomposes rapidly in alkaline media, with a half-life in the range of a few min. Curcumin photodegrades in organic solvents (33). In total, $\sim 80 \%$ of a typical oral dose of curcumin passes unaltered through the gastrointestinal tract, and the majority of the absorbed compound ends up metabolized in the intestinal mucosa and liver (33). These properties limit the applications of curcumin as a bioactive agent.

To overcome the limitations of poor solubility, researchers have examined various strategies. Creating complexes of curcumin with cyclodextrins may significantly improve its water solubility and its stability under alkaline conditions, although such complexation decreases the photostability of curcumin $(33,34)$. Stability of curcumin against alkaline hydrolysis may additionally be improved by encapsulating it in micelles composed of cationic surfactants, including cetyl trimethylammonium bromide and dodecyl trimethylammonium bromide $(33,34)$.

Emulsion-based delivery systems have been demonstrated to stabilize active ingredients and increase their bioavailability (35), and the same is true for curcumin; conjugating it with phosphatidylcholine increases its bioavailability five-fold. Mono-polyethylene glycolylation of curcumin produces pro-drugs that are stable in buffer at a physiological $\mathrm{pH}$ and readily release curcumin into human plasma (36).

Curcumin derivatization has additionally led to promising drug compounds. Based on structure-activity studies of the tautomeric forms of curcumin, the diketone system was modified to generate two curcumin analogs, benzyloxime and isoxazole (37). These analogs have demonstrated much greater antitumor potency against MCF-7 breast cancer cells and

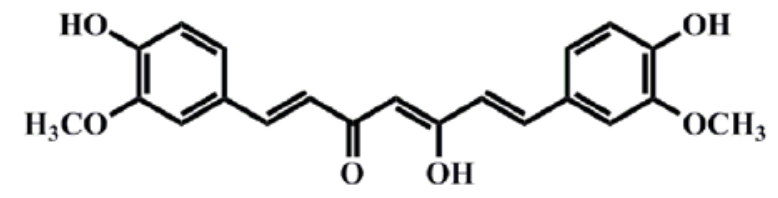

Figure 1. Chemical structure of curcumin.

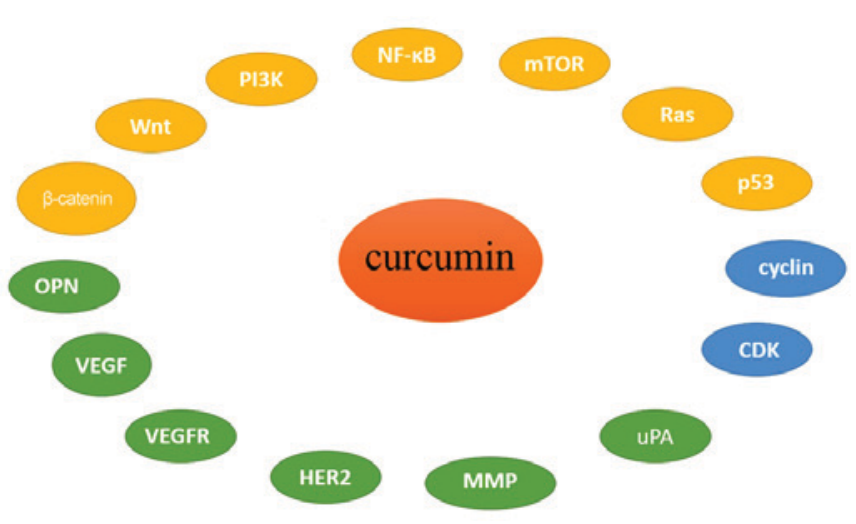

Figure 2. Molecular targets of curcumin. PI3K, phosphatidylinositol-3-kinase; $\mathrm{NF}-\kappa \mathrm{B}$, nuclear factor- $\kappa \mathrm{B}$; mTOR, mammalian target or rapamycin; CDK, cyclin-dependent kinase; uPA, urinary plasminogen activator; MMP, matrix metalloproteinase; human epidermal growth factor receptor 2; VEGFR, vascular endothelial growth factor receptor; VEGF, vascular endothelial growth factor; OPN, osteopontin. Yellow indicates transcription factors and signaling molecules; green indicates tumor angiogenesis and growth-associated proteins; blue indicates molecules associated with tumor proliferation.

multidrug-resistant transfected MCF-7 cells (37). Furthermore, these curcumin analogs potently reduce expression of B-cell lymphoma-extra large (Bcl-xL), B cell lymphoma 2 (Bcl-2) and cyclooxygenase- 2 in the two cell lines (38).

Curcumin polymers (polycurcumins) have high drug loading efficiency and may be used as backbone-type conjugates to stabilize and solubilize curcumin in water (39). Tang et al (39) prepared high-molecular-weight curcumin polycurcumins through condensation polymerization of curcumin. Polyacetal-based polycurcumin is highly cytotoxic to MCF-7 breast cancer cell lines and to SKOV-3 intraperitoneal xenograft tumors $(40,41)$. This condensation approach protected curcumin from hydrolysis at all $\mathrm{pH}$ values examined, and from ultraviolet degradation. Loading curcumin into mixed polymeric micelles improved its oral bioavailability $\sim 55$-fold (42).

\section{Molecular targets of curcumin for breast cancer therapy}

Curcumin inhibits breast cancer cell proliferation by the following mechanisms: i) Inducing cell cycle arrest and p53-dependent apoptosis; ii) altering expression of signaling proteins, including Ras, phosphatidylinositol-3-kinase (PI3K), protein kinase B (Akt), mammalian target of rapamycin (mTOR) and Wnt/ $\beta$-catenin; iii) downregulating transcription factors; and iv) inhibiting tumor growth and angiogenesis (Fig. 2).

Effects of curcumin on CDK/cyclin complexes. CDKs are serine/threonine kinases that control cell cycle progression by forming a complex with their respective cyclin partners $(43,44)$. Altered expression of CDKs, overexpression of cyclins and 
loss of expression of CDK inhibitors are frequently observed in malignant cells (44). Dysregulated CDK activity provides cancer cells with a selective growth advantage. In this way, dysregulated overexpression of cyclin D1 triggers progression of aggressive breast cancer (45). Previous studies in mammary epithelial carcinoma cells suggest that curcumin inhibits cell cycle progression by blocking the association of cyclin D1 with CDK4, thus reducing cyclin D1 activity (46,47). In MCF-7 breast cancer cells, curcumin reduces cell proliferation by arresting cells in $\mathrm{G}_{1}$ phase. The drug achieves this arrest by stimulating the proteosomal degradation of cyclin $\mathrm{E}$ and upregulating CDK inhibitors, p53, p21 and p27; the addition of specific proteosomal inhibitors suppresses these effects of curcumin (48). Cyclin $\mathrm{E}$ is a nuclear protein that serves an important role in $\mathrm{G}_{1} / \mathrm{S}$ progression by interacting with its catalytic partner, CDK2, and by interacting with the retinoblastoma $(\mathrm{Rb})$ protein $(49,50)$. It appears likely that the anti-proliferative effects of curcumin are due to proteasome-mediated downregulation of cyclin $\mathrm{E}$ and upregulation of CDK inhibitors (51).

The anti-proliferative effects of curcumin appear to be selective to cells overexpressing CDK 2. In mammary carcinoma cells, curcumin induces p53-dependent apoptosis and causes $\mathrm{G}_{2}$ phase arrest. However, in normal human mammary cells, curcumin causes $\mathrm{G}_{0}$ cell cycle arrest by blocking the association between CDK 4 and $\mathrm{CDK}$ 6, and inhibiting the phosphorylation of $\mathrm{Rb}$ (52). In this way, curcumin also prevents the initiation of p53-mediated apoptosis, which occurs only in cells arrested in $\mathrm{G}_{2}$ phase (52).

Effects of curcumin on the p53 pathway. The p53 protein is one of the most important tumor suppressor proteins, regulating a wide range of cellular processes, including cell proliferation, DNA damage and apoptosis (53). It is encoded by the tumor protein $p 53$ gene, which is frequently mutated in numerous types of human cancer (53), leading to loss of cell proliferative control, DNA check points and DNA repair mechanisms. As a result, cancer cells become immortal. Restoring the function of p53 is an attractive therapeutic strategy in cancer therapy (54).

Curcumin induces apoptosis in breast cancer cells via p53-dependent and -independent pathways. For instance, curcumin arrests the cell cycle and induces p53-dependent apoptosis in MCF-7 breast cancer cells (55). Notably, curcumin exerts no anti-proliferative effects on MDAH041 cells lacking p53 or on TR9-7 cells that express p53 at low levels; rather, its effects are most notable in p53-expressing TR9-7 and MCF-7 cells. Expression of the pro-apoptotic protein apoptosis regulator $\mathrm{Bax}(\mathrm{Bax})$ is also higher in curcumin-treated MCF-7 cells. These results suggest that curcumin exerts its anti-proliferative effects via p53-dependent and p53-independent pathways $(55,56)$.

Targets of curcumin in Ras signaling. Ras is a small transmembrane protein belonging to the large GTPase family of enzymes that hydrolyze guanosine triphosphate in order to transduce signals inside the cell (57). Mammalian cells have three Ras proteins (K-, H- and N-Ras), each of which serves a different function (57). Blocking oncogenic Ras signaling is an attractive strategy in cancer therapy.
Curcumin has been extensively studied for its effects on oncogenic Ras signaling pathways. In MCF-10A human breast epithelial cells transformed using H-Ras, curcumin induces reactive oxygen species production, which downregulates activity of matrix metalloproteinase (MMP)-2 and Bcl-2 and upregulates the activity of Bax and caspase-3 (58).

Potentially acting through a similar mechanism, curcumin arrests Ras-transfected HAG-1 human adenocarcinoma cells in $\mathrm{G}_{2} / \mathrm{M}$ phase by inducing expression of extracellular signal-regulated kinase $1 / 2$ and Bax, and reducing expression of Bcl-xL. These results suggest that curcumin may be a potent therapy against Ras-overexpressing cancer (59). Preclinical studies in animals, and ultimately clinical trials, are required to clarify the therapeutic effect of curcumin in Ras-induced cancer.

Targets of curcumin in PI3K/Akt/mTOR signaling. PI3Ks are a family of lipid kinases that phosphorylate inositol phospholipids and generate the secondary messenger phosphatidylinositol-3,4,5-trisphosphate in the plasma membrane (60). PI3K interacts with Akt to trigger the latter's translocation inside the cytoplasm. Activated Akt interacts with a number of substrates to perform numerous functions in cell survival, cell cycle progression and cell growth (60). Constitutive expression of PI3K and Akt, in addition to silencing of phosphatase and tensin homolog and glycogen synthase kinase $3 \beta$ (GSK3 $\beta$ ), are frequently observed in a number of human malignancies. Therefore, PI3K/Akt-mediated signaling is an attractive target in cancer chemotherapy $(61,62)$.

Cancer cells survive for a prolonged time by activating survival pathways involving PI3K, Akt and mTOR, in addition to anti-apoptotic pathways involving Bcl-2. Targeting survival and apoptosis pathways is likely to be essential for controlling highly metastatic breast cancer. Curcumin on its own weakly stimulates apoptosis in breast cancer cells; however, combining it with the PI3K-specific inhibitor LY294002 stimulates apoptosis more strongly $(63,64)$. The authors of these previous studies hypothesized that the PI3K obstruction overcomes the oncogenic expression of Bcl-2. Further studies are required to verify whether curcumin may inhibit $\mathrm{PI} 3 \mathrm{~K} / \mathrm{Akt} / \mathrm{mTOR}$ signaling in breast cancer cells and identify the mechanism(s) involved.

Targets of curcumin in Wnt/ $\beta$-catenin signaling. Wnts are a family of secreted glycoproteins that regulate multiple signaling pathways through $\beta$-catenin-dependent and -independent mechanisms (65-67). Wnts serve a crucial role in development, survival and metabolism. Inappropriate regulation and hyperactivation of $\mathrm{Wnt} / \beta$-catenin signaling have been implicated in numerous human malignancies. Overexpression of $\beta$-catenin leads to constitutive activation of cell proliferation (68), and tumor cells downregulate the tumor suppressor GSK $3 \beta$, which limits the activity of $\beta$-catenin by triggering its ubiquitin-mediated proteosomal degradation. Therefore, targeting the $\mathrm{Wnt} / \beta$-catenin signaling pathway is an attractive approach in cancer therapy $(69,70)$.

In MCF-7 and MDA-MB-231 cells, curcumin arrests the cell cycle in $\mathrm{G}_{2} / \mathrm{M}$ cells by modulating $\mathrm{Wnt} / \beta$-catenin signaling. In these cells, curcumin upregulates GSK3 $\beta$ and causes loss of nuclear $\beta$-catenin. Loss of nuclear $\beta$-catenin 
results in a loss of its downstream target cyclin D1 (71). This suggests that, at least in MCF-7 and MDA-MB-231 cells, the antitumor effects of curcumin are due to abrogation of Wnt/ $\beta$-catenin signaling (71).

Targets of curcumin among nuclear factor- $\kappa B(N F-\kappa B)$ transcription factors. NF- $\mathrm{kB}$ is a family of transcription factors that are involved in the immune response and inflammation. Gene expression profiling studies suggest that the NF- $\mathrm{kB}$ pathway is a key regulator in triple-negative breast cancer (TNBC), with activation of NF- $\mathrm{KB}$ signaling strongly implicated in the pathogenesis of specific TNBCs (72-74). Cytoplasmic NF-kB is bound to a group of inhibitory proteins known as inhibi-

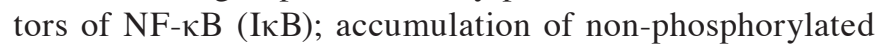
I $\mathrm{B}$ prohibits the translocation of NF- $\mathrm{NB}$ from cytoplasm to nucleus, resulting in inactivation of NF- $\kappa B$ and its downstream targets (74). NF- $\mathrm{kB}$ promotes the transcription of numerous key regulators of cancer invasion and progression, including cytokines, chemokines, cell adhesion molecules and inducible pro-inflammatory enzymes (74). In addition, NF- $\kappa B$ has been postulated to be a useful marker of the epithelial-mesenchymal transition (EMT) and invasiveness in breast cancer (19).

A number of previous studies suggest that curcumin inhibits NF- $\kappa \mathrm{B}$ expression and therefore additional downstream signaling pathways, ultimately leading to the silencing of inflammatory cytokines, including chemokine (C-X-C motif) ligand (CXCL)1 and CXCL2 (19); and to alterations in the expression of MMP-9, urokinase plasminogen activator (uPA), uPA receptor, intercellular adhesion molecule 1 and chemokine receptor $4(3,72,75)$. In this manner, curcumin is likely to inhibit the growth and invasion of breast cancer, in part, by downregulating NF- $\mathrm{KB}$ signaling pathways.

Curcumin may modulate the expression of NF- $\mathrm{kB}$ target genes $(76,77)$, which include $\mathrm{Bcl}-2$, ornithine decarboxylase (ODC) and c-myc, which are associated with apoptosis or cell survival (78). For example, ODC is the rate-limiting enzyme in polyamine biosynthesis and curcumin has been demonstrated to suppress ODC activity and inhibit cell proliferation (79). Activation of the NF- $\mathrm{KB} / \mathrm{Bcl}-2$ pathway is associated with drug resistance in cancer cells (80).

Accumulating evidence suggests that targeting NF- $\kappa \mathrm{B}$ to inhibit cell growth and reverse EMT may be a novel therapeutic strategy in breast cancer.

Targets of curcumin in tumor angiogenesis. Angiogenesis is the normal physiological mechanism by which novel blood vessels are formed from pre-existing blood vessels. It occurs during embryogenesis, menstruation and wound healing (81). Angiogenesis in tumors is crucial for cancer progression. Tumor cells procure nutrients for their uncontrolled growth through tumor angiogenesis (81). Tumor cells constitutively produce pro-angiogenic factors, including vascular endothelial growth factor(VEGF) and basic fibroblast growth factor, which curcumin may inhibit in order to modulate tumor angiogenesis $(81,82)$.

Curcumin inhibits angiogenesis and growth of breast cancer tumors implanted into nude mice. These effects are associated with downregulated expression of a number of VEGF isomers, including VEGF-A, VEGF-C and VEGF receptor 2, in addition to decreased microvessel density (83). These results are in agreement with other previous studies demonstrating that suppression of VEGF function inhibits breast tumor growth $(83,84)$. In nude mice, which were implanted with MDA-MB-231 tumors and treated with osteopontin (OPN; additionally termed secreted phosphoprotein 1) to stimulate angiogenesis, curcumin blocked NF- $\kappa \mathrm{B} /$ cyclic AMP-dependent transcription factor ATF-4 binding and prevented $\mathrm{OPN}$-induced upregulation of VEGF (85). This suggests that curcumin acts as a potent anti-angiogenic agent in regulating OPN-induced tumor angiogenesis in breast cancer.

\section{Potential risks and adverse side effects of curcumin}

Curcumin causes blood thinning, which may decrease blood flow and increase the risk of ischemic stroke (86). It may also inhibit the ability of chemotherapeutics to induce production of reactive oxygen species and block the c-Jun NH2-terminal kinase pathway. In fact, curcumin may exert pro-oxidant effects, similar to numerous other anti-oxidants (87).

Curcumin significantly inhibits cyclophosphamide-induced regression of human breast cancer xenografts in mice $(88,89)$. In cultures of MCF-7, MDA-MB-231 and BT-474 human breast cancer cells, curcumin may inhibit the ability of camptothecin, mechlorethamine and doxorubicin to induce apoptosis by $\leq 70 \%(18,90)$. Curcumin may also serve as an iron chelator to inhibit hypoxia inducible factor- $\alpha$ prolyl hydroxylase activity (91). Therefore, further research is urgently required to establish whether patients with breast cancer undergoing chemotherapy should limit their intake of curcumin.

\section{Conclusion}

The available evidence suggests that curcumin, a polyphenolic compound derived from the dietary spice turmeric, is a non-toxic, highly promising natural anti-oxidant that exerts anticancer effects by targeting multiple molecules and pathways. By affecting different targets, curcumin modulates numerous cancer hallmarks, including cell proliferation, cancer signaling pathways, transcription factors and tumor angiogenesis. Curcumin may have applications as a novel drug in the near future to control various diseases, particularly breast cancer.

The clinical use of curcumin is limited by its poor bioavailability; however, specific novel derivatives have been prepared that may improve patient responses. Research is in progress on nanotechnology-based formulations and delivery systems to improve curcumin pharmacokinetics. Possibilities include encapsulating curcumin into polymeric or lipid micelles, or liposomes, and combining or conjugating curcumin to ligands or antibodies that may target cancer cell receptors or other epitopes. Novel curcumin analogs and nanotechnology-based formulations may overcome the limitations of oral administration of curcumin.

\section{Acknowledgements}

Not applicable.

\section{Funding}

Supported by the Henan Science and Technology Innovation Team, Investigation on Plant Resources in Dabie Mountains 
and the study and utilization of active components of special plants (grant no. 2017083), Nanhu Scholars Program for Young Scholars of Xinyang Normal University (Xinyang, China; grant no. 2018001).

\section{Availability of data and materials}

Not applicable.

\section{Authors' contributions}

XS conceived and designed the article. MZ and ED read the literature and collated the appropriate information. XS and YL wrote the paper.

\section{Ethics approval and consent to participate}

Not applicable.

\section{Patient consent for publication}

Not applicable.

\section{Competing interests}

The authors declare that they have no competing interests.

\section{References}

1. Garcia-Aranda $\mathrm{M}$ and Redondo M: Protein kinase targets in breast cancer. Int J Mol Sci 18: pii: E2543, 2017.

2. Sun YS, Zhao Z, Yang ZN, Xu F, Lu HJ, Zhu ZY, Shi W, Jiang J, Yao PP and Zhu HP: Risk factors and preventions of breast cancer. Int J Biol Sci 13: 1387-1397, 2017.

3. Ye JC and Formenti SC: Integration of radiation and immunotherapy in breast cancer - Treatment implications. Breast 38: 66-74, 2018.

4. Kasi PD, Tamilselvam R, Skalicka-Woźniak K, Nabavi SF, Daglia M, Bishayee A, Pazoki-Toroudi H and Nabavi SM: Molecular targets of curcumin for cancer therapy: An updated review. Tumour Biol 37: 13017-13028, 2016.

5. Williams GH and Stoeber K: The cell cycle and cancer. J Pathol 226 : 352-364, 2012

6. Fulda S: Modulation of apoptosis by natural products for cancer therapy. Planta Med 76: 1075-1079, 2010.

7. Tan W, Lu J, Huang M, Li Y, Chen M, Wu G, Gong J, Zhong Z, $\mathrm{Xu} \mathrm{Z}$, Dang Y, et al: Anti-cancer natural products isolated from chinese medicinal herbs. Chin Med 6: 27, 2011.

8. Demain AL and Vaishnav P: Natural products for cancer chemotherapy. Microb Biotechnol 4: 687-699, 2011.

9. Yuan R, Hou Y, Sun W, Yu J, Liu X, Niu Y, Lu JJ and Chen X: Natural products to prevent drug resistance in cancer chemotherapy: A review. Ann N Y Acad Sci 1401: 19-27, 2017.

10. Messner DJ, Robinson T and Kowdley KV: Curcumin and turmeric modulate the tumor-promoting effects of iron in vitro. Nutr Cancer 69: 481-489, 2017.

11. Hou J and Cui HL: In Vitro antioxidant, antihemolytic and anticancer activity of the carotenoids from halophilic archaea. Curr Microbiol 75: 266-271, 2018.

12. Nabavi SM, Marchese A, Izadi M,Curti V, Daglia M and Nabavi SF: Plants belonging to the genus Thymus as antibacterial agents: from farm to pharmacy. Food Chem 173: 339-347, 2015.

13. Yang HL, Korivi M, Lin MK, Chang HC, Wu CR, Lee MS, Chen WT and Hseu YC: Antihemolytic and antioxidant properties of pearl powder against 2,2'-azobis(2-amidinopropane) dihydrochloride-induced hemolysis and oxidative damage to erythrocyte membrane lipids and proteins. J Food Drug Anal 25: 898-907, 2017

14. Hirapara H, Ghori V, Anovadiya A, Baxi S and Tripathi C: Effects of ethanolic extract of Jasminum grandiflorum Linn. Flowers on wound healing in diabetic Wistar albino rats. Avicenna J Phytomed 7: 401-408, 2017.
15. Nomura EC, Rodrigues MR, da Silva CF, Hamm LA, Nascimento AM, de Souza LM, Cipriani TR, Baggio CH and Werner MF: Antinociceptive effects of ethanolic extract from the flowers of Acmella oleracea (L.) R.K. Jansen in mice. J Ethnopharmacol 150: 583-589, 2013.

16. Nabavi SM, Habtemariam S, Nabavi SF, Sureda A, Daglia M, Moghaddam AH and Amani MA: Protective effect of gallic acid isolated from Peltiphyllum peltatum against sodium fluoride-induced oxidative stress in rat's kidney. Mol Cell Biochem 372: 233-239, 2013.

17. Fadus MC, Lau C, Bikhchandani J and Lynch HT: Curcumin: An age-old anti-inflammatory and anti-neoplastic agent. J Tradit Complement Med 7: 339-346, 2016.

18. Banik U, Parasuraman S, Adhikary AK and Othman NH: Curcumin: The spicy modulator of breast carcinogenesis. J Exp Clin Cancer Res 36: 98, 2017.

19. Shishodia S, Sethi G and Aggarwal BB: Curcumin: Getting back to the roots. Ann N Y Acad Sci 1056: 206-217, 2005.

20. Aggarwal BB, Kumar A and Bharti AC: Anticancer potential of curcumin: Preclinical and clinical studies. Anticancer Res 23. 363-398, 2003.

21. Han X, Deng S, Wang N, Liu Y and Yang X: Inhibitory effects and molecular mechanisms of tetrahydrocurcumin against human breast cancer MCF-7 cells. Food Nutr Res 60: 30616 , 2016.

22. Liu JL, Pan YY, Chen O, Luan Y, Xue X, Zhao JJ, Liu L and Jia HY: Curcumin inhibits MCF-7 cells by modulating the $\mathrm{NF}-\kappa \mathrm{B}$ signaling pathway. Oncol Lett 14: 5581-5584, 2017.

23. Zheng J, Zhou Y, Li Y, Xu DP, Li S and Li HB: Spices for prevention and treatment of cancers. Nutrients 8: pii: E495, 2016.

24. Wang Y, Yu J, Cui R, Lin J and Ding X: Curcumin in treating breast cancer: A review. J Lab Autom 21: 723-731, 2016.

25. Imran M, Ullah A, Saeed F, Nadeem M, Arshad MU and Suleria HAR: Cucurmin, anticancer, \& antitumor perspectives: A comprehensive review. Crit Rev Food Sci Nutr 58: 1271-1293, 2018.

26. Ko EY and Moon A: Natural products for chemoprevention of breast cancer. J Cancer Prev 20: 223-231, 2015.

27. Hossain DM, Bhattacharyya S, Das T and Sa G: Curcumin: The multi-targeted therapy for cancer regression. Front Biosci (Schol Ed) $4: 335-355,2012$.

28. Zhou H, Beevers CS and Huang S: The targets of curcumin. Curr Drug Targets 12: 332-347, 2011.

29. Huang G, Xu Z, Huang Y, Duan X, Gong W, Zhang Y, Fan J and He F: Curcumin protects against collagen-induced arthritis via suppression of BAFF production. J Clin Immunol 33: 550-557, 2013.

30. Schneider C, Gordon ON, Edwards RL and Luis PB: Degradation of curcumin: From mechanism to biological implications. J Agric Food Chem 63: 7606-7614, 2015.

31. Jamil QUA, Jaerapong N, Zehl M, Jarukamjorn K and Jäger W: Metabolism of curcumin in human breast cancer cells: Impact of sulfation on cytotoxicity. Planta Med 83: 1028-1034, 2017.

32. Vera-Ramirez L, Perez-Lopez P, Varela-Lopez A, Ramirez-Tortosa M, Battino M and Quiles JL: Curcumin and liver disease. Biofactors 39: 88-100, 2013.

33. Marin E, Briceño MI, Torres A and Caballero-George C: New curcumin-loaded chitosan nanocapsules: In vivo evaluation. Planta Med 83: 877-883, 2017.

34. Feng T, Wei Y, Lee RJ and Zhao L: Liposomal curcumin and its application in cancer. Int J Nanomedicine 12: 6027-6044, 2017.

35. Tamvakopoulos C, Dimas K, Sofianos ZD, Hatziantoniou S, Han Z, Liu ZL, Wyche JH and Pantazis P: Metabolism and anticancer activity of the curcumin analogue, dimethoxycurcumin. Clin Cancer Res 13: 1269-1277, 2007.

36. Venkateswarlu S, Ramachandra MS and Subbaraju GV: Synthesis and biological evaluation of polyhydroxycurcuminoids. Bioorg Med Chem 13: 6374-6380, 2005.

37. Nagaraju GP, Aliya S, Zafar SF, Basha R, Diaz R and El-Rayes BF: The impact of curcumin on breast cancer. Integr Biol (Camb) 4: 996-1007, 2012.

38. Labbozzetta M, Notarbartolo M, Poma P, Maurici A, Inguglia L, Marchetti P, Rizzi M, Baruchello R, Simoni D and D'Alessandro N: Curcumin as a possible lead compound against hormone-independent, multidrug-resistant breast cancer. Ann N Y Acad Sci 1155: 278-283, 2009.

39. Tang H, Murphy CJ,Zhang B, Shen Y, Van Kirk EA, Murdoch WJ and Radosz M: Curcumin polymers as anticancer conjugates. Biomaterials 31: 7139-7149, 2010. 
40. Catania A, Barrajón-Catalán E, Nicolosi S, Cicirata F and Micol V: Immunoliposome encapsulation increases cytotoxic activity and selectivity of curcumin and resveratrol against HER2 overexpressing human breast cancer cells. Breast Cancer Res Treat 141: 55-65, 2013.

41. Bayet-Robert M and Morvan D: Metabolomics reveals metabolic targets and biphasic responses in breast cancer cells treated by curcumin alone and in association with docetaxel. PLoS One 8 : e57971, 2013.

42. Patil S, Choudhary B, Rathore A, Roy K and Mahadik K: Enhanced oral bioavailability and anticancer activity of novel curcumin loaded mixed micelles in human lung cancer cells. Phytomedicine 22: 1103-1111, 2015.

43. Frouin I, Montecucco A, Biamonti G, Hübscher U, Spadari S and Maga G: Cell cycle-dependent dynamic association of cyclin/Cdk complexes with human DNA replication proteins. EMBO J 21: 2485-2495, 2002.

44. John PC, Mews M and Moore R: Cyclin/Cdk complexes: Their involvement in cell cycle progression and mitotic division. Protoplasma 216: 119-142, 2001.

45. Villegas SL, Darb-Esfahani S, von Minckwitz G, Huober J, Weber K, Marmé F, Furlanetto J, Schem C, Pfitzner BM, Lederer B, et al: Expression of cyclin D1 protein in residual tumor after neoadjuvant chemotherapy for breast cancer. Breast Cancer Res Treat 168: 179-187, 2018.

46. Lamb R, Lehn S, Rogerson L, Clarke RB and Landberg G: Cell cycle regulators cyclin D1 and CDK4/6 have estrogen receptor-dependent divergent functions in breast cancer migration and stem cell-like activity. Cell Cycle 12: 2384-2394, 2013.

47. Peurala E, Koivunen P, Haapasaari KM, Bloigu R and Jukkola-Vuorinen A: The prognostic significance and value of cyclin D1, CDK4 and p16 in human breast cancer. Breast Cancer Res 15: R5, 2013.

48. Aggarwal BB, Banerjee S, Bharadwaj U, Sung B, Shishodia S and Sethi G: Curcumin induces the degradation of cyclin E expression through ubiquitin-dependent pathway and up-regulates cyclin-dependent kinase inhibitors p21 and p27 in multiple human tumor cell lines. Biochem Pharmacol 73: 1024-1032, 2007.

49. Doostan I, Karakas C, Kohansal M, Low KH, Ellis MJ, Olson JA Jr, Suman VJ, Hunt KK, Moulder SL and Keyomarsi K Cytoplasmic cyclin E mediates resistance to aromatase inhibitors in breast cancer. Clin Cancer Res 23: 7288-7300, 2017.

50. Mazumder S, DuPree EL and Almasan A: A dual role of cyclin E in cell proliferation and apoptosis may provide a target for cancer therapy. Curr Cancer Drug Targets 4: 65-75, 2004

51. Keyomarsi K, Tucker SL, Buchholz TA, Callister M, Ding Y, Hortobagyi GN, Bedrosian I, Knickerbocker C, Toyofuku W, Lowe M, et al: Cyclin E and survival in patients with breast cancer. N Engl J Med 347: 1566-1575, 2002.

52. Choudhuri T, Pal S, Das T and Sa G: Curcumin selectively induces apoptosis in deregulated cyclin D1-expressed cells at G2 phase of cell cycle in a p53-dependent manner. J Biol Chem 280 20059-20068, 2005.

53. Kandoth C, McLellan MD, Vandin F, Ye K, Niu B, Lu C, Xie M Zhang Q, McMichael JF, Wyczalkowski MA, et al: Mutational landscape and significance across 12 major cancer types. Nature 502: 333-339, 2013.

54. Muller PA and Vousden KH: Mutant p53 in cancer: New functions and therapeutic opportunities. Cancer Cell 25: 304-317, 2014.

55. Fan H, Liang Y, Jiang B, Li X, Xun H, Sun J, He W, Lau HT and Ma X: Curcumin inhibits intracellular fatty acid synthase and induces apoptosis in human breast cancer MDA-MB-231 cells. Oncol Rep 35: 2651-2656, 2016.

56. Choudhuri T, Pal S, Agwarwal ML, Das T and Sa G: Curcumin induces apoptosis in human breast cancer cells through p53-dependent Bax induction. FEBS Lett 512: 334-340, 2002.

57. Adjei AA: Blocking oncogenic Ras signaling for cancer therapy. J Natl Cancer Inst 93: 1062-1074, 2001

58. Kim MS, Kang HJ and Moon A: Inhibition of invasion and induction of apoptosis by curcumin in H-ras-transformed MCF10A human breast epithelial cells. Arch Pharm Res 24: 349-354, 2001.

59. Ono M, Higuchi T, Takeshima M, Chen $C$ and Nakano S: Differential anti-tumor activities of curcumin against Ras- and Src-activated human adenocarcinoma cells. Biochem Biophys Res Commun 436: 186-191, 2013.

60. Ettl T, Schwarz-Furlan S, Haubner F, Müller S, Zenk J, Gosau M, Reichert TE and Zeitler K: The PI3K/AKT/mTOR signalling pathway is active in salivary gland cancer and implies different functions and prognoses depending on cell localisation. Oral Oncol 48: 822-830,2012.
61. Chen WC, Lai YA, Lin YC, Ma JW, Huang LF, Yang NS, Ho CT, Kuo SC and Way TD: Curcumin suppresses doxorubicin-induced epithelial-mesenchymal transition via the inhibition of TGF- $\beta$ and PI3K/AKT signaling pathways in triple-negative breast cancer cells. J Agric Food Chem 61: 11817-11824, 2013.

62. Carnero A, Blanco-Aparicio C, Renner O, Link W and Leal JF: The PTEN/PI3K/AKT signalling pathway in cancer, therapeutic implications. Curr Cancer Drug Targets 8: 187-198, 2008.

63. Akkoc Y, Berrak Ö, Arisan ED, Obakan P, Çoker-Gürkan A and Palavan-Ünsal N: Inhibition of PI3K signaling triggered apoptotic potential of curcumin which is hindered by $\mathrm{Bcl}-2$ through activation of autophagy in MCF-7 cells. Biomed Pharmacother 71: $161-171,2015$

64. Yu S, Shen G, Khor TO, Kim JH and Kong AN: Curcumin inhibits Akt/mammalian target of rapamycin signaling through protein phosphatase-dependent mechanism. Mol Cancer Ther 7: 2609-2620, 2008.

65. Zou YF, Xie CW, Yang SX and Xiong JP: AMPK activators suppress breast cancer cell growth by inhibiting DVL3-facilitated Wnt/ $\beta$-catenin signaling pathway activity. Mol Med Rep 15: 899-907, 2017.

66. Pohl SG, Brook N, Agostino M, Arfuso F, Kumar AP and Dharmarajan A: Wnt signaling in triple-negative breast cancer. Oncogenesis 6: e310, 2017.

67. Kwon YJ, Leibovitch BA, Bansal N, Pereira L, Chung CY, Ariztia EV, Zelent A, Farias EF and Waxman S: Targeted interference of SIN3A-TGIF1 function by SID decoy treatment inhibits Wnt signaling and invasion in triple negative breast cancer cells. Oncotarget 8: 88421-88436, 2016.

68. Ma X, Zhao X, Yan W, Yang J, Zhao X, Zhang H, Hui Y and Zhang S: Tumor-infiltrating lymphocytes are associated with $\beta$-catenin overexpression in breast cancer. Cancer Biomark 21: 639-650, 2018

69. Roy A, Ansari SA, Das K, Prasad R, Bhattacharya A, Mallik S, Mukherjee A and Sen P: Coagulation factor VIIa-mediated protease-activated receptor 2 activation leads to $\beta$-catenin accumulation via the AKT/GSK3 $\beta$ pathway and contributes to breast cancer progression. J Biol Chem 292: 13688-13701, 2017.

70. Gao S, Ge A, Xu S, You Z, Ning S, Zhao Y and Pang D: PSAT1 is regulated by ATF4 and enhances cell proliferation via the GSK $3 \beta / \beta$-catenin/cyclin D1 signaling pathway in ER-negative breast cancer. J Exp Clin Cancer Res 36: 179, 2017.

71. Prasad CP, Rath G, Mathur S, Bhatnagar D and Ralhan R: Potent growth suppressive activity of curcumin in human breast cancer cells: Modulation of Wnt/beta-catenin signaling. Chem Biol Interact 181: 263-271, 2009 .

72. Poma P, Labbozzetta M, D'Alessandro N and Notarbartolo M: NF-kB is a potential molecular drug target in triple-negative breast cancers. OMICS 21: 225-231, 2017.

73. Pires BR, Mencalha AL, Ferreira GM, de Souza WF, Morgado-Diaz JA, Maia AM, Corrêa S and Abdelhay ES: NF-kappaB is involved in the regulation of EMT genes in breast cancer cells. PLoS One 12: e0169622, 2017.

74. Park YH: The nuclear factor-kappa B pathway and response to treatment in breast cancer. Pharmacogenomics 18: 1697-1709, 2017.

75. Stanic Z: Curcumin, a compound from natural sources, a true scientific challenge-a review. Plant Foods Hum Nutr 72: 1-12, 2017.

76. Murray-Stewart $\mathrm{T}$ and Casero RA: Regulation of polyamine metabolism by curcumin for cancer prevention and therapy. Med Sci (Basel) 5: pii: E38, 2017.

77. Oyagbemi AA, Saba AB and Ibraheem AO: Curcumin: From food spice to cancer prevention. Asian Pac J Cancer Prev 10: 963-967, 2009.

78. Leu TH and Maa MC: The molecular mechanisms for the antitumorigenic effect of curcumin. Curr Med Chem Anticancer Agents 2: 357-370, 2002.

79. Gafner S, Lee SK, Cuendet M, Barthélémy S, Vergnes L, Labidalle S, Mehta RG, Boone CW and Pezzuto JM: Biologic evaluation of curcumin and structural derivatives in cancer chemoprevention model systems. Phytochemistry 65: 2849-2859, 2004.

80. Qian C, Li P, Yan W, Shi L, Zhang J, Wang Y, Liu H and You Y: Downregulation of osteopontin enhances the sensitivity of glioma U251 cells to temozolomide and cisplatin by targeting the NF-кB/Bcl2 pathway. Mol Med Rep 11: 1951-1955, 2015.

81. Shehzad A, Qureshi M, Anwar MN and Lee YS: Multifunctional curcumin mediate multitherapeutic effects. J Food Sci 82: 2006-2015, 2017 
82. Arablou T and Kolahdouz-Mohammadi R: Curcumin and endometriosis: Review on potential roles and molecular mechanisms. Biomed Pharmacother 97: 91-97, 2018.

83. Carroll CE, Ellersieck MR and Hyder SM: Curcumin inhibits MPA-induced secretion of VEGF from T47-D human breast cancer cells. Menopause 15: 570-574, 2008

84. Saberi-Karimian M, Katsiki N, Caraglia M, Boccellino M, Majeed M and Sahebkar A: Vascular endothelial growth factor: An important molecular target of curcumin. Crit Rev Food Sci Nutr: 1-14, 2017 (Epub ahead of print).

85. Chakraborty G, Jain S, Kale S, Raja R, Kumar S, Mishra R and Kundu GC: Curcumin suppresses breast tumor angiogenesis by abrogating osteopontin-induced VEGF expression. Mol Med Rep 1: 641-646, 2008.

86. DeBusk RM: Dietary supplements and cardiovascular disease. Curr Atheroscler Rep 2: 508-514, 2000.

87. Kawanishi S, Oikawa S and Murata M: Evaluation for safety of antioxidant chemopreventive agents. Antioxid Redox Signal 7 : 1728-1739, 2005.
88. Di Martino RM, Luppi B, Bisi A, Gobbi S, Rampa A, Abruzzo A and Belluti F: Recent progress on curcumin-based therapeutics: A patent review (2012-2016). Part I: Curcumin. Expert Opin Ther Pat 27: 579-590, 2017.

89. Di Martino RMC, Bisi A, Rampa A, Gobbi S and Belluti F: Recent progress on curcumin-based therapeutics: A patent review (2012-2016). Part II: Curcumin derivatives in cancer and neurodegeneration. Expert Opin Ther Pat 27: 953-965, 2017.

90. Somasundaram R, Jacob L, Swoboda R, Caputo L, Song H, Basak S, Monos D, Peritt D, Marincola F, Cai D, et al: Inhibition of cytolytic T lymphocyte proliferation by autologous CD4+/CD25+ regulatory $\mathrm{T}$ cells in a colorectal carcinoma patient is mediated by transforming growth factor-beta. Cancer Res 62: 5267-5272, 2002.

91. Strofer M, Jelkmann W, Metzen E, Brockmeier U, Dunst J and Depping R: Stabilisation and knockdown of HIF-two distinct ways comparably important in radiotherapy. Cell Physiol Biochem 28: 805-812, 2011. 